\title{
Donor hepatectomy time influences ischemia-reperfusion injury of the biliary tree in donation after circulatory death liver transplantation
}

\author{
Otto B. van Leeuwen, BSc ${ }^{\mathrm{a}}$, Marjolein van Reeven, MSc ${ }^{\mathrm{b}}$, Danny van der Helm, $\mathrm{MSc}^{\mathrm{c}}$, \\ Jan N.M. IJzermans, MD, $\mathrm{PhD}^{\mathrm{b}}$, Vincent E. de Meijer, $\mathrm{MD}, \mathrm{PhD}^{\mathrm{a}}$, \\ Aad P. van den Berg, MD, PhD ${ }^{\mathrm{d}}$, Sarwa Darwish Murad, MD, PhD ${ }^{\mathrm{e}}$, \\ Bart van Hoek, $\mathrm{MD}, \mathrm{PhD}^{\mathrm{c}}$, Ian P.J. Alwayn, $\mathrm{MD}, \mathrm{PhD}^{\mathrm{f}}$, Robert J. Porte, $\mathrm{MD}, \mathrm{PhD}^{\mathrm{a}}$, \\ Wojciech G. Polak, MD, PhD ${ }^{\mathrm{b}, *}$ \\ a Division of HPB Surgery \& Liver Transplantation, Department of Surgery, University of Groningen, University Medical Center Groningen, the Netherlands \\ b Department of Surgery, Division of HPB and Transplant Surgery, Erasmus MC University Medical Center Rotterdam, the Netherlands \\ ${ }^{c}$ Department of Gastroenterology and Hepatology, Leiden University Medical Center, the Netherlands \\ ${ }^{\mathrm{d}}$ Department of Gastroenterology and Hepatology, University of Groningen, University Medical Center Groningen, the Netherlands \\ e Department of Gastroenterology and Hepatology, Erasmus MC University Medical Center Rotterdam, the Netherlands \\ ${ }^{\mathrm{f}}$ Department of Surgery, Division of Transplant Surgery, Leiden University Medical Center, the Netherlands
}

\section{A R T I C L E I N F O}

\section{Article history:}

Accepted 10 February 2020

Available online $\mathrm{xxx}$

\begin{abstract}
A B S T R A C T
Background: Donor hepatectomy time is associated with graft survival after liver transplantation. The aim of this study was to identify the impact of donor hepatectomy time on biliary injury during donation after circulatory death liver transplantation.

Methods: First, bile duct biopsies of livers included in (pre)clinical machine perfusion research were analyzed. Secondly, of the same livers, bile samples were collected during normothermic machine perfusion. Lastly, a nationwide retrospective cohort study was performed including 273 adult patients undergoing donation after circulatory death liver transplantation between January 1, 2002 and January 1, 2017. Primary endpoint was development of non-anastomotic biliary strictures within 2 years of donation after circulatory death liver transplantation. Cox proportional-hazards regression analyses were used to assess the influence of hepatectomy time on the development of non-anastomotic biliary strictures.

Results: Livers with severe histological bile duct injury had a higher median hepatectomy time $(P=.03)$. During normothermic machine perfusion, livers with a hepatectomy time $>50$ minutes had lower biliary bicarbonate and bile pH levels. In the nationwide retrospective study, donor hepatectomy time was an independent risk factor for non-anastomotic biliary strictures after donation after circulatory death liver transplantation (Hazard Ratio 1.18 per 10 minutes increase, 95\% Confidence Interval 1.06-1.30, $P$ value $=.002$ )

Conclusion: Donor hepatectomy time negatively influences histological bile duct injury before normothermic machine perfusion and bile composition during normothermic machine perfusion. Additionally, hepatectomy time is a significant independent risk factor for the development of non-anastomotic biliary strictures after donation after circulatory death liver transplantation.
\end{abstract}

() 2020 Elsevier Inc. All rights reserved.
Otto B. van Leeuwen and Marjolein van Reeven shared first authorship. Both authors contributed equally to this manuscript. Robert J. Porte and Wojciech G. Polak shared last authorship. Both authors contributed equally to this manuscript.

* Reprint requests: Wojciech G. Polak, MD, PhD, Erasmus University Medical Center, Department of Surgery, PO Box 2040, 3000 CA Rotterdam, The Netherlands.

E-mail address: w.polak@erasmusmc.nl (W.G. Polak).

\section{Introduction}

The imbalance between the number of patients on the waiting list for liver transplantation (LT) and the number of available grafts from donation after brain death (DBD) donors has resulted in an increased use of livers from donation after circulatory death (DCD) 
donors. In 2018, 38\% of all deceased donor LT in the Netherlands were performed with a DCD graft. ${ }^{1}$

LT from DCD donors can lead to inferior outcomes compared with LT with DBD grafts, especially with respect to graft survival, ${ }^{2-5}$ which is related to a higher chance of developing early allograft dysfunction and post-transplant cholangiopathy. ${ }^{6-10}$ Among posttransplant cholangiopathies, non-anastomotic strictures (NAS), also known as ischemic type biliary lesions or ischemic cholangiopathy, is the most hazardous type, with a strong negative impact on graft survival. ${ }^{11-13}$

An important determinant of outcome after LT is ischemia reperfusion injury. Ischemia reperfusion injury occurs in both DBD and DCD-LT. However, DCD grafts suffer from an additional period of warm ischemia in the donor between withdrawal of life support and initiation of cold flush out, the so-called donor warm ischemia time (dWIT). Several studies have indicated that the length of the dWIT is a critical risk factor for negative outcome after DCD-LT. 2,14,15

Unfortunately, the start of in situ cold flush out and cooling does not lead to adequate protection against ischemic injury, because the core temperature of the liver generally does not drop below 15 to $20^{\circ} \mathrm{C}$ during surgery. ${ }^{16}$ At this temperature, organs are still metabolically active, resulting in rapid depletion of adenosine triphosphate and accumulation of metabolites during anaerobic metabolism. Liver core temperature first reaches a relatively safe range $\left(<4^{\circ} \mathrm{C}\right)$ when organs are stored in a bag with cold preservation solution in a box with ice. Therefore, it is hypothesized that, apart from the dWIT, the duration of the hepatectomy time provides an additional risk factor for ischemic injury and could therefore impact outcome after LT.

A recent study published by Jochmans et al and based on data from the Eurotransplant Registry supported this hypothesis. ${ }^{17}$ In this study, donor hepatectomy time was an independent risk factor for patient mortality and graft loss. Moreover, DCD grafts appeared to be more susceptible to donor hepatectomy time than DBD grafts. More recently, Farid et al assessed the influence of the donor hepatectomy time on the outcomes of DCD-LT in the United Kingdom, concluding that a hepatectomy time of more than 60 minutes was associated with a higher risk of primary nonfunction and graft failure. ${ }^{18}$ Neither study, however, assessed the effect of donor hepatectomy time on the development of post-transplant cholangiopathy after DCD-LT, neither did they evaluate whether hepatectomy time was different among procurement teams.

Several studies have shown a strong relation between bile duct injury (BDI) before implantation and the development of NAS after transplantation. ${ }^{19,20}$ If donor hepatectomy time influences the rates of NAS, this would be displayed in the severity of biliary injury before implantation. Additionally, bile composition during normothermic machine perfusion (NMP) of liver grafts can be studied to assess bile duct injury. ${ }^{21,22}$

The aim of this study was to assess the impact of donor hepatectomy time in DCD donors on the development of biliary injury during DCD-LT. First, bile duct biopsies taken upon arrival in one of the 3 recipient centers were analyzed. Secondly, bile composition during NMP was studied. Last, the influence of hepatectomy time on the development of NAS after DCD-LT was studied in a nationwide retrospective database study.

\section{Methods}

\section{Donation procedure and organ procurement}

Until recently, all donor procedures/procurements in the Netherlands were performed by one of 5 regional procurement teams, each covering a certain region of the country. Each procurement team consists of a surgeon, surgical assistant, anesthesiologist, and 2 operation room assistants. In the Netherlands, withdrawal of life support in a patient eligible for DCD organ donation generally takes place at the intensive care unit. Premortem cannulation of the patient is not performed, and systemic heparinization is prohibited by Dutch law. When circulatory arrest has been determined, there is a mandatory 5 minutes "notouch" period. After this "no-touch" period, the donor is transported to the operating theatre. A super-rapid sterno-laparotomy with pressurized, aortic-only perfusion is used as the standard procurement technique. Cold perfusion is currently executed with Belzer UW Cold Storage Solution (Bridge to Life, London, UK) Whether the liver is retrieved separately or en bloc with the pancreas is based on the preferences of the surgeon. On the back table, the liver is flushed via the portal vein with at least $500 \mathrm{~mL}$ cold preservation solution until clear perfusate is established. The common bile duct (CBD) and intrahepatic biliary tree are flushed with low pressure Belzer UW Cold Storage Solution. ${ }^{23}$ As there are no clear Dutch guidelines on the sequence of organ procurement, the lungs in a DCD donor are usually procured before the abdominal organs. The implantation is usually executed with a caval sideclamp and veno-venous anastomosis, end-to-end arterial and portal anastomosis, and duct-to-duct biliary anastomosis. The standard reperfusion technique used is initial portal vein reperfusion.

\section{Study design}

This study consists of 3 parts. First, bile duct biopsies and bile composition of DCD livers were analyzed for a potential influence of hepatectomy time (parts $\mathrm{A}-\mathrm{B}$ ). Hereafter, to validate the findings, a nationwide retrospective database analysis was performed (part C).

\section{Part A: Histological analysis of bile ducts}

Of all DCD livers that underwent preclinical and clinical NMP in the University Medical Center Groningen between January 1, 2013 and January 1, 2019, bile duct biopsies before machine perfusion were collected. The only criterion required for inclusion was that the donor hepatectomy time was available. Biopsies were taken from the distal CBD before machine perfusion, fixed in $4 \%$ formalin, and subsequently embedded in paraffin. Slices of $4 \mu \mathrm{m}$ were cut and stained with hematoxylin and eosin and subsequently examined using light microscopy. The BDI score was determined in a blinded fashion by 2 researchers, using a clinically relevant histological grading system. ${ }^{20,22}$ The BDI consisted of the combined scores for deep peribiliary gland injury, peribiliary vascular plexus injury, and stroma necrosis. The cutoff value used between low and high BDI was 4.75 , as described previously. ${ }^{22}$ Comparisons between groups were performed with the $\chi^{2}$ test or Fisher exact test where appropriate. Receiver operating characteristic curves were used to identify the most appropriate cutoff values.

\section{Part B: Normothermic machine perfusion}

All preclinical and clinical NMP procedures were performed with the Liver Assist device (Organ Assist, Groningen, the Netherlands). Protocols and outcomes are reported elsewhere. ${ }^{2,24,25}$ To monitor biliary tree viability, bile was collected from an $8 \mathrm{Fr}$ biliary drain in the CBD. During NMP, bile samples were collected every 30 minutes under mineral oil to determine biliary $\mathrm{pH}$, bicarbonate, and glucose, as these parameters are biomarkers of bile duct viability. ${ }^{22}$ Bile composition was compared between the groups at different time points using the Mann-Whitney U test. 

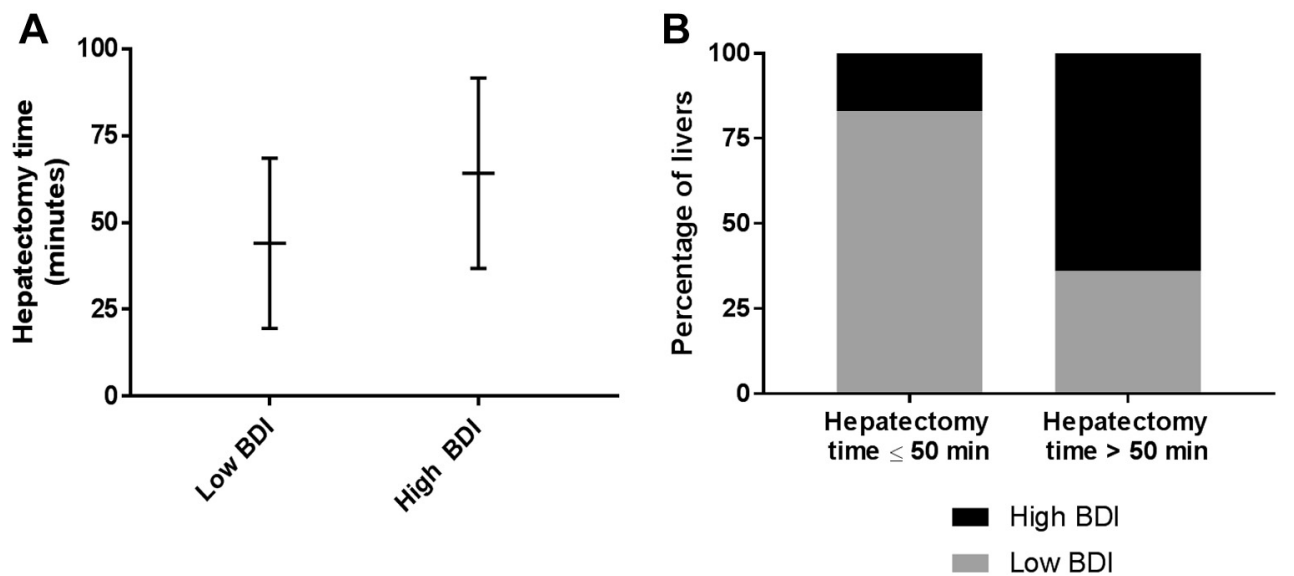

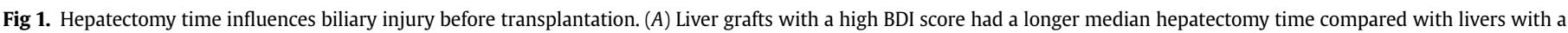

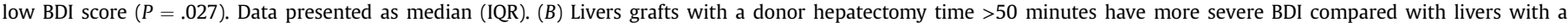
hepatectomy time $\leq 50$ minutes $(P=.016)$. *Depicts a significant $(P<.050)$ difference.

\section{Part C: Retrospective nationwide study}

In this nationwide retrospective cohort study, all adult LT performed with a DCD graft in the Netherlands between January 1, 2002 and January 1, 2017 were included. Exclusion criteria were multiorgan DCD transplants, DCD retransplantations, transplantations involving machine perfusion, and procurement of DCD grafts by a foreign procurement team. Additionally, cases with missing information on hepatectomy times or donor agonal phase were excluded. Donor characteristics and information on the procurement procedure and the regional procurement team were obtained via the Donor Data Application of Eurotransplant. Data of recipients and transplantation outcomes were obtained from the databases of the participating centers and were completed with data from the patients' electronic medical records.

Donor hepatectomy time was defined as the period between the start of cold flush in the donor and the storage of the liver in a bowl with cold preservation fluid and melting ice on the back-table. The dWIT was calculated as the time between withdrawal of life support and cold flush in the donor. Since in the normal situation the donor hepatectomy time is part of the cold ischemia time, the definition of the cold ischemia time has been altered to minimize the chance of confounding; cold ischemia time was defined as the period between the end of the donor hepatectomy and the removal of the liver from ice before implantation. Finally, recipient warm ischemia time was defined as the time between removal of the liver from ice until either portal or arterial reperfusion, whichever came first.

The endpoint of the retrospective study was the development of NAS within 2 years after transplantation. NAS was defined as donor bile duct strictures at any location but the anastomosis, in absence of hepatic artery thrombosis. To meet the endpoint, patients were required to have clinical symptoms of cholestasis (eg, jaundice, itch, elevated total bilirubin) with subsequent imaging demonstrating bile duct strictures. If NAS developed after 2 years, it was considered to be related to recipient factors rather than donor factors. Univariable and multivariable Cox proportional-hazards regression models were used to evaluate independent risk factors for NAS. In both models, subjects that did not develop NAS within 2 years were censored at 2 years post transplantation. Patients who died or underwent retransplantation within the first 2 years after transplantation were censored at their date of death or date of retransplantation, respectively. Variables were included in the multivariable, backward stepwise, Cox model if univariable Cox regression yielded a $P$ value $<.20$. The threshold of .20 was chosen to decrease the risk of overfitting of the model. The reported hazard ratios (HR) for donor hepatectomy time refer to an increase of 10 minutes in hepatectomy time. For the cold ischemia time and recipient warm ischemia time, the HR represent an increase of 1 hour and 1 minute, respectively.

In all 3 projects incorporated in this study, continuous variables were presented as median with both total range and interquartile range (IQR), whereas categorical variables were presented as number [percentage]. All tests had a 2 -sided design with a $P$ value below .05 considered significant. The analyses were performed using SPSS version 24 (IBM Corporation, Chicago, IL). This study was approved by the Medical Ethical Committee of the University Medical Center Groningen (METC.2017/504).

\section{Results}

\section{Part A: Histological analysis of the bile duct}

Of 40 consecutive NMP procedures between 2013 and 2019, 39 bile duct biopsies were collected. After exclusion of biopsies with an unknown donor hepatectomy time, 27 biopsies were included in the analysis. Livers with a high BDI score had a significantly longer median donor hepatectomy time compared with grafts with low BDI score (56 vs 44 minutes, $P=.03$ ) (Fig 1 , A). Receiver operating characteristic-curve analysis showed a donor hepatectomy time of 50 minutes as the most suitable cutoff point. Of livers with hepatectomy time $\leq 50$ minutes, $17 \%$ displayed high BDI vs $64 \%$ in livers with a hepatectomy time $>50$ minutes $(P=.01)($ Fig $1, B)$.

\section{Part B: Normothermic machine perfusion}

Of the 27 livers, livers with a hepatectomy time $\leq 50$ minutes had more alkalotic bile during the first 4 hours of NMP. Subsequently, biliary bicarbonate levels were higher in livers with a hepatectomy time below 50 minutes. (Fig 2, $A-B$ ). Glucose reabsorption, displayed by the glucose ratio between bile and perfusate, did not seem to be significantly influenced by hepatectomy time (Fig 2, C). 

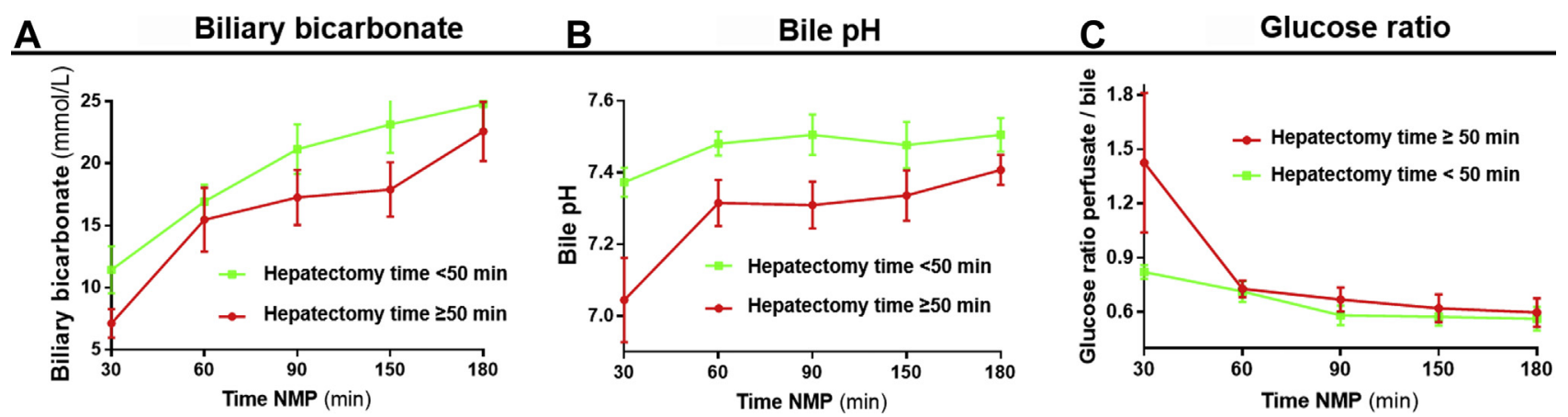

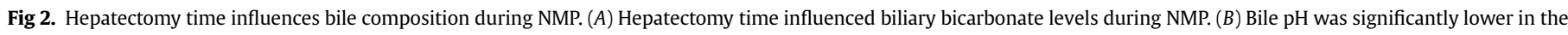

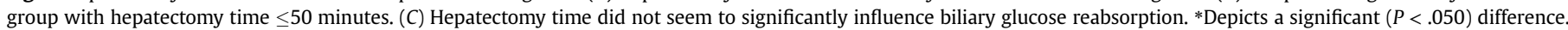

\section{Part C: Retrospective study}

A total of 376 DCD-LTs were performed in the Netherlands between January 1, 2002 and January 1, 2017. One hundred and three cases met 1 or more of the exclusion criteria, resulting in a total of 273 included in this study (Fig 3). The median follow-up period of the complete cohort was 4.36 years (IQR 2.81-7.08, range 0-16.8 years). Baseline characteristics are presented in Table I. Median donor hepatectomy time for the entire cohort was 63 minutes (IQR $52.5-80.5$, range $23-140$ minutes). Lung procurement led to a significantly longer donor hepatectomy time of 69 minutes (IQR 59-80 minutes), when compared with a hepatectomy time of 61 minutes (IQR 49-81 minutes) in donors in which lungs were not procured $(P=.02)$. The outcomes after DCD-LT in the complete cohort are shown in Table I. Actuarial 1-, 3-, and 5-year graft survival rates were $75 \%, 64 \%$, and $60 \%$, and $87 \%, 79 \%$, and $74 \%$ for patient survival, respectively.

Sixty-six patients $(24.2 \%)$ were diagnosed with NAS within 2 years of LT. During the complete follow-up, 25 patients have undergone a retransplantation as a result of this complication. Baseline characteristics, stratified by recipient development of NAS, are provided in supplementary Table I. In a univariable Cox proportional-hazards regression model, donor hepatectomy time was an independent risk factor for the development of NAS (HR $1.14,95 \%$ confidence interval $[\mathrm{CI}] 1.03-1.26, P$ value .02$)$. After adjusting for all covariates with a $P$ value below .2 in univariable analyses, donor hepatectomy time remained an independent risk factor for developing NAS within the first 2 years post LT (adjusted

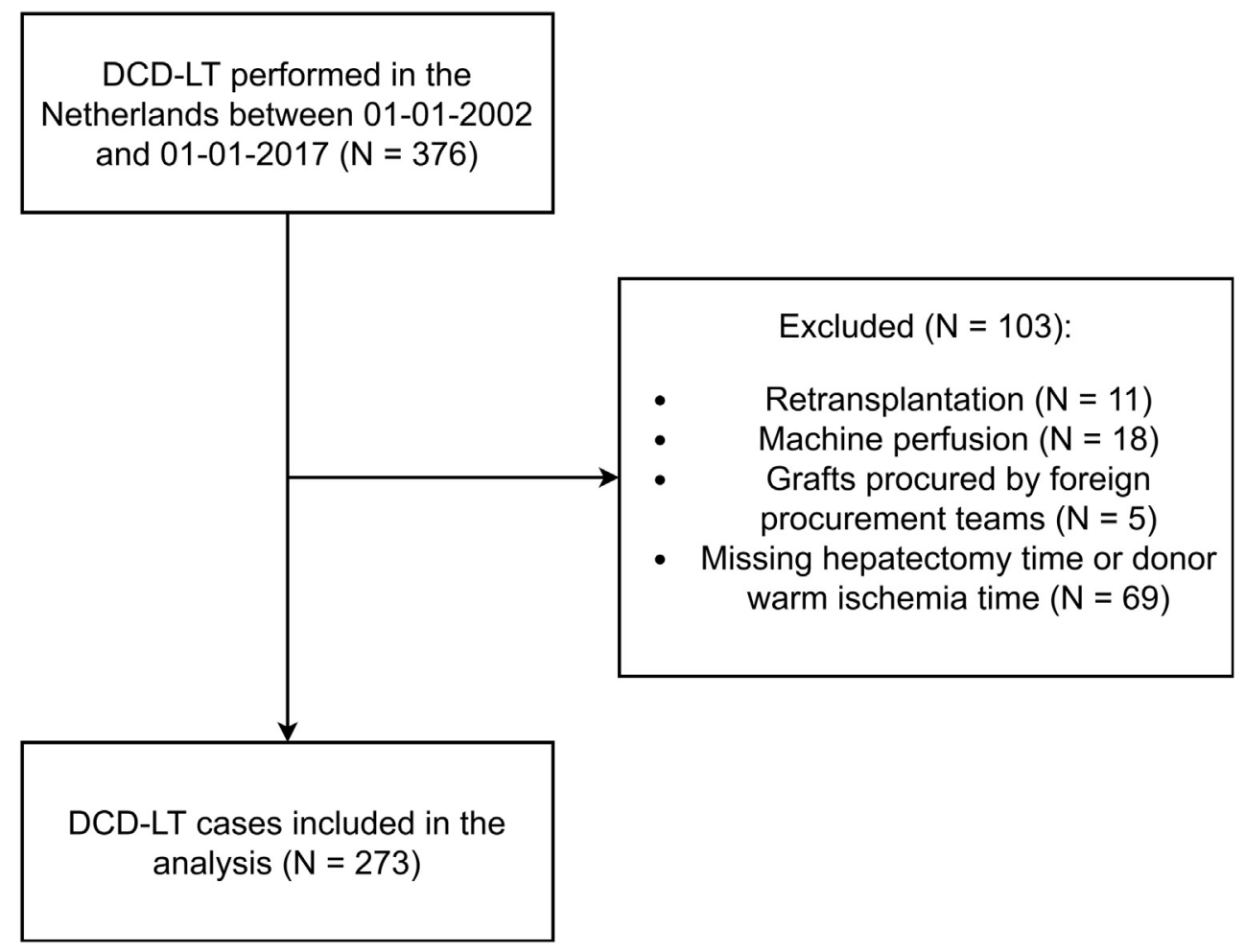

Fig 3. Flow chart of included subjects in the retrospective database study. 
Table I

Donor and recipient demographics

\begin{tabular}{|c|c|}
\hline Characteristic & Result $(N=273)$ \\
\hline \multicolumn{2}{|l|}{ Donor } \\
\hline Age (y) & $\begin{array}{l}47.0(35.5-54.0) \\
\text { Range } 12-74\end{array}$ \\
\hline \multicolumn{2}{|l|}{ Sex } \\
\hline Male & $155[56.8 \%]$ \\
\hline Female & $118[43.2 \%]$ \\
\hline Body mass index $\left(\mathrm{kg} / \mathrm{m}^{2}\right)$ & $\begin{array}{l}24.0(22.0-26.0) \\
\text { Range } 13-34\end{array}$ \\
\hline \multicolumn{2}{|l|}{ CVA as cause of death } \\
\hline No & $151[55.3 \%]$ \\
\hline Yes & $122[44.7 \%]$ \\
\hline \multirow[t]{2}{*}{ ALT peak $(\mathrm{U} / \mathrm{L})$} & $43.0(23.0-87.0)$ \\
\hline & Range $6-7,385$ \\
\hline \multirow[t]{2}{*}{ Last $\gamma \mathrm{GT}(\mathrm{U} / \mathrm{L})$} & $34.0(20.0-65.5)$ \\
\hline & Range $4-747$ \\
\hline \multicolumn{2}{|l|}{ Procurement } \\
\hline \multirow[t]{2}{*}{ Donor warm ischemia time (min) } & $32.0(26.0-38.0)$ \\
\hline & Range $15-80$ \\
\hline \multirow[t]{2}{*}{ Donor hepatectomy time $(\mathrm{min})^{\dagger}$} & $63.0(52.5-80.5)$ \\
\hline & Range $23-140$ \\
\hline Lung procurement & $84.0[30.8 \%]$ \\
\hline \multicolumn{2}{|l|}{ Recipient } \\
\hline \multirow{2}{*}{ Age $(y)$} & $57.0(49.0-63.0)$ \\
\hline & Range $22-70$ \\
\hline \multicolumn{2}{|l|}{ Sex } \\
\hline Male & 197 [72.2\%] \\
\hline \multirow{3}{*}{$\begin{array}{l}\text { Female } \\
\text { Body mass index }\left(\mathrm{kg} / \mathrm{m}^{2}\right)\end{array}$} & $76[27.8 \%]$ \\
\hline & $25.7(23.4-29.1)$ \\
\hline & Range $17-46$ \\
\hline \multicolumn{2}{|l|}{ HCC as indication for transplantation } \\
\hline No & $175[64.1 \%]$ \\
\hline & 98 [35.9\%] \\
\hline \multirow{2}{*}{ Laboratory MELD score } & $14.6(10.0-21.0)$ \\
\hline & Range $6-44$ \\
\hline \multicolumn{2}{|l|}{ Transplantation } \\
\hline \multirow[t]{2}{*}{ Cold ischemia time (min) } & $359(302-431)$ \\
\hline & Range $131-743$ \\
\hline \multirow[t]{2}{*}{ Recipient warm ischemia time $(\mathrm{min})^{\S}$} & $34.0(26.0-42.0)$ \\
\hline & Range $17-144$ \\
\hline Outcomes & \\
\hline AST peak $(\mathrm{u} / \mathrm{L})$ & $2,115(1,165-4,252)$ \\
\hline & Range $129-20,280$ \\
\hline ALT peak $(\mathrm{u} / \mathrm{L})$ & $1,620(771-2,857)$ \\
\hline & Range $162-10,944$ \\
\hline Intensive care unit stay (d) & $2.0(1.0-5.0)$ \\
\hline & Range $0-185$ \\
\hline Total hospital stay (d) & $18.0(13.0-27.0)$ \\
\hline & Range $0-235$ \\
\hline Primary non-function ${ }^{\|}$ & $8[2.90 \%]$ \\
\hline Non-anastomotic strictures & $70[25.6 \%]$ \\
\hline Within 2 y post-transplantation & $66[24.2 \%]$ \\
\hline Hepatic artery thrombosis & $14[5.10 \%]$ \\
\hline Actuarial graft survival & \\
\hline $1 \mathrm{y}$ & $75 \%$ \\
\hline $3 y$ & $64 \%$ \\
\hline $5 \mathrm{y}$ & $60 \%$ \\
\hline Actuarial patient survival & \\
\hline $1 \mathrm{y}$ & $87 \%$ \\
\hline $3 \mathrm{y}$ & $79 \%$ \\
\hline $5 \mathrm{y}$ & $74 \%$ \\
\hline
\end{tabular}

Values are presented as median (IQR) or number [\%].

$A L T$, alanine aminotransferase; AST, aspartate aminotransferase; CVA, cerebrovascular accident; $\gamma G T$, gamma-glutamyl transferase; HCC, hepatocellular carcinoma; $M E L D$, model for end-stage liver disease.

* The time between withdrawal of life support and cold flush in the donor.

$\dagger$ The period of time between the start of cold flush in the donor and the storage of the liver on ice on the back table.

$\ddagger$ The time between the end of the donor hepatectomy and the removal of the liver from ice before implantation.

$\S$ The time between removal of the liver from ice until either portal or arterial reperfusion.

II Patient death or retransplantation within 7 days of transplantation without clear cause.
HR 1.18, 95\% CI 1.06-1.30, $P$ value .002, Tables II and III). Besides hepatectomy time, donor age and cold ischemia time were significant risk factors for NAS.

\section{Discussion}

This is the first study that demonstrates the impact of donor hepatectomy time on the development of biliary injury during and after DCD liver transplantation. Hepatectomy time influences the severity of histological BDI before transplantation. Moreover, prolonged hepatectomy times negatively influences bile composition during NMP. Additionally, the retrospective study indicates that every 10-minute increase in donor hepatectomy time leads to an $18 \%$ increase in the risk of developing NAS.

Op den Dries et al have shown that bile duct histology is highly predictive of NAS after liver transplantation. ${ }^{20}$ In the current study, it is observed that prolonged hepatectomy times leads to an increased BDI score, depicting increased rates of deep peribiliary gland injury, peribiliary vascular plexus injury, and stroma necrosis. The results from this histology study demonstrate that the impact of hepatectomy time is already visible before graft reperfusion. In addition to histology, NMP can be used to assess biliary function. ${ }^{21,22}$ Similar results were observed during NMP; livers with prolonged hepatectomy time produced bile of inferior quality.

The results of the current study are roughly in line with those reported in the Eurotransplant registry study by Jochmans et al and the United Kingdom-based study from Farid et al: a prolonged donor hepatectomy time impairs the outcome of DCD-LT. However, neither of the studies were able to assess the influence of donor hepatectomy time on the development of biliary complications. Surprisingly, the median donor hepatectomy time in the Dutch cohort in the current study was substantially longer than that of the DCD-LT subgroup in the study of Jochmans et al (63 vs 50 minutes). ${ }^{17}$ As within the Eurotransplant region, only the Netherlands, Belgium, and Austria perform DCD organ procurements; this implies that the donor hepatectomy time in the Netherlands is substantially longer compared with the other 2 countries. Moreover, the median hepatectomy time in our cohort was also considerably longer than in the United Kingdom as reported by Farid et al (63 vs 35 minutes). ${ }^{18}$ As a result of this finding, the Dutch Committee on Independent Procurement Teams implemented several strategies to lower the hepatectomy time, such as raising awareness on the impact of the donor hepatectomy time and endorsing knowledge and skill exchange between the teams. Since 2018, this has resulted in a substantial decrease of the donor hepatectomy time in the Netherlands (mean of 42 minutes with a standard deviation of 12 minutes) without an increase in liver injuries, highlighting the importance of training in organ procurement and regular evaluation. $^{26}$

The graft survival rates reported by Farid et al are substantially higher than those in our cohort (1-, 3-, and 5-year graft survival of $86.5 \%, 80.9 \%$, and $77.7 \%$ in the United Kingdom vs $75 \%, 64 \%$, and $60 \%$ in the Dutch cohort, Table I). Since the patient survival rates have not been reported by Farid et al, it is not possible to evaluate whether the higher rate of graft loss in the Netherlands is the result of more patient deaths or of more retransplantations. However, it could possibly be explained by the difference in hepatectomy time between the 2 cohorts. Nevertheless, it would be valuable to thoroughly investigate this substantial difference in graft survival rates.

Surprisingly, procurement of the lungs seemed to have a protective effect on the development of NAS, despite the fact that lung 
Table II

Univariable Cox proportional-hazards regression model for developing NAS

\begin{tabular}{|c|c|c|c|}
\hline & Hazard ratio & $95 \% \mathrm{CI}$ & $P$ value \\
\hline \multicolumn{4}{|l|}{ Donor } \\
\hline Age (y) & 1.03 & $1.01-1.05$ & .004 \\
\hline \multicolumn{4}{|l|}{ Sex } \\
\hline Male & REF & & \\
\hline Female & 1.14 & $0.70-1.86$ & .59 \\
\hline Body mass index $\left(\mathrm{kg} / \mathrm{m}^{2}\right)$ & 0.99 & $0.92-1.08$ & .88 \\
\hline \multicolumn{4}{|l|}{ CVA as cause of death } \\
\hline No & REF & & \\
\hline Yes & 1.83 & $1.13-2.98$ & .02 \\
\hline ALT peak $(\mathrm{U} / \mathrm{L})$ & 1.00 & $1.00-1.00$ & .09 \\
\hline Last $\gamma \mathrm{GT}(\mathrm{U} / \mathrm{L})$ & 1.00 & $1.00-1.00$ & .41 \\
\hline \multicolumn{4}{|l|}{ Procurement } \\
\hline Donor warm ischemia time $(\mathrm{min})^{*}$ & 1.03 & $1.01-1.05$ & .01 \\
\hline Donor hepatectomy time $(10 \mathrm{~min})^{\dagger}$ & 1.14 & $1.03-1.26$ & .02 \\
\hline Lung procurement & 0.60 & $0.34-1.06$ & .08 \\
\hline \multicolumn{4}{|l|}{ Recipient } \\
\hline Age (y) & 0.994 & $0.97-1.02$ & .60 \\
\hline \multicolumn{4}{|l|}{ Sex } \\
\hline Male & REF & & \\
\hline Female & 1.22 & $0.72-2.07$ & .45 \\
\hline Body mass index $\left(\mathrm{kg} / \mathrm{m}^{2}\right)$ & 1.02 & $0.97-1.07$ & .55 \\
\hline \multicolumn{4}{|l|}{$\mathrm{HCC}$ as indication for transplantation } \\
\hline No & REF & & \\
\hline Yes & 0.77 & $0.46-1.30$ & .33 \\
\hline Laboratory MELD score & 0.98 & $0.95-1.02$ & .35 \\
\hline \multicolumn{4}{|l|}{ Transplantation } \\
\hline Cold ischemia time $(h)^{\ddagger}$ & 1.17 & $1.04-1.33$ & .01 \\
\hline Recipient warm ischemia time $(\mathrm{min})^{5}$ & 1.02 & $1.00-1.04$ & .17 \\
\hline
\end{tabular}

Values are presented as median (IQR) or number [\%].

$A L T$, alanine aminotransferase; CVA, cerebrovascular accident; $\gamma G T$, gamma-glutamyl transferase; HCC, hepatocellular carcinoma; MELD, model for end-stage liver disease; $P B C$, primary biliary cirrhosis; $P S C$, primary sclerosing cholangitis.

* The time between withdrawal of life support and cold flush in the donor.

$\dagger$ The period of time between the start of cold flush in the donor and the storage of the liver on ice on the back table.

$\ddagger$ The time between the end of the donor hepatectomy and the removal of the liver from ice before implantation.

$\S$ The time between removal of the liver from ice until either portal or arterial reperfusion.

procurement leads to a prolonged hepatectomy time. This finding is probably the result of the strict acceptance criteria for DCD lung donation handled by thoracic surgeons and lung physicians. Only

Table III

Multivariable Cox proportional-hazards regression model for NAS

\begin{tabular}{llll}
\hline & Hazard ratio & $95 \% \mathrm{CI}$ & $P$ value \\
\hline $\begin{array}{l}\text { Donor } \\
\quad \text { Age (y) }\end{array}$ & 1.03 & $1.01-1.05$ & .01 \\
$\quad$ CVA as cause of death & - & - & .29 \\
$\quad$ No & & & \\
$\quad$ Yes & 1.00 & $1.00-1.00$ & .05 \\
$\quad$ ALT Peak & - & & .50 \\
$\begin{array}{l}\text { Procurement } \\
\quad \text { Donor warm ischemia time }\end{array}$ & 1.18 & - & .002 \\
$\quad \begin{array}{l}\text { Donor hepatectomy time } \\
\quad \text { Lung procurement }\end{array}$ & 0.47 & $0.26-0.84$ & .01 \\
$\quad \begin{array}{l}\text { Transplantation } \\
\quad \text { Cold ischemia time }\end{array}$ & 1.22 & $1.08-1.38$ & .001 \\
$\quad$ Recipient warm ischemia time & - & - & .47 \\
\hline
\end{tabular}

Multivariable model was conducted via backward stepwise approach. A dash indicates that variable was removed from the model.

$A L T$, alanine aminotransferase; CVA, cerebrovascular accident; $\gamma G T$, gammaglutamyl transferase.

* The time between withdrawal of life support and cold flush in the donor.

$\dagger$ The period of time between the start of cold flush in the donor and the storage of the liver on ice on the back table.

$\ddagger$ The time between the end of the donor hepatectomy and the removal of the liver from ice before implantation.

$\S$ The time between removal of the liver from ice until either portal or arterial reperfusion. lungs from optimal DCD donors are accepted, otherwise the lungs are not procured. Lung procurement is in that case a proxy for a more optimal donor.

Jochmans et al stated that portal perfusion, next to standard in situ aortic cold flush, can accelerate liver cooling and might prevent the detrimental effect of prolonged hepatectomy time. ${ }^{17}$ In a recent published study, Hameed et al concluded that in high-risk DBD donors, dual perfusion is superior. ${ }^{27}$ Furthermore, Ghinolfi et al concluded recently that dual perfusion has a protective effect on the development of ischemic type biliary lesions after LT with grafts from octogenarian donors. ${ }^{28}$ However, a randomized controlled trial comparing aortic flush only and combined aortic and portal flush in DBD-LT, showed no difference in the incidence of post-transplant cholangiopathy. ${ }^{29}$ Since DCD grafts could also be considered as high-risk grafts, it would be justifiable to evaluate the effect of dual perfusion versus aortic only perfusion in the DCD-LT population. Another method to potentially minimize the detrimental effect of both dWIT and hepatectomy time on the outcomes after LT is the use of normothermic regional perfusion. A recently published study by Hessheimer et al showed that with the use of normothermic regional perfusion the rates of biliary complications and graft loss could be reduced substantially when compared with a super-rapid recovery. ${ }^{30}$

Recently, Kalisvaart et al showed the importance of the agonal phase of the DCD donor and its influence on the outcomes after transplantation, considering an arterial oxygen saturation level below $80 \%$ as starting point for the functional donor warm ischemia 
time. ${ }^{31}$ Unfortunately, in our cohort, data on blood pressures and saturation during the agonal phase were unavailable or improperly recorded. Therefore, we were forced to use another definition of the donor warm ischemia time. Since the agonal phase has proven to be of importance, we chose to use the period between withdrawal of life support and the initiation of cold flushing as the dWIT in this study rather than the time between cardiac arrest and cold perfusion. Additionally, as shown before, this study also underlines the importance of a short cold ischemia time for DCD grafts. ${ }^{22.32}$ Every hour of cold ischemia was associated with a $22 \%$ increased risk of NAS. Finally, donor age is once again shown to be an important risk factor for biliary complications.

An important strength of this study is the fact that histological analyses are combined with a study of bile composition during NMP and a nationwide retrospective database study. Another strength is that donor hepatectomy time is incorporated as a continuous variable into the multivariable model rather than as a dichotomous variable set around a certain cutoff for donor hepatectomy time. This latter would have led to a loss of valuable information. Another strong aspect of this study is the follow-up of all patients with detailed information on the development of biliary complications. One limitation of the database study is the retrospective design and relatively small cohorts. In addition, as part $C$ was used to validate the findings in parts A and B, these cohorts consist of different patients. Moreover, in a substantial number of cases, hepatectomy time and/or dWIT was missing, leading to a high exclusion rate. Since we could not guarantee these variables to be missing at random, imputation of these variables was not desirable. We do not suspect that our results were confounded by this; however, bias cannot entirely be excluded.

In conclusion, donor hepatectomy time strongly influences biliary injury during and after DCD-LT. The donor hepatectomy time should be kept as short as possible, especially in the presence of other risk factors such as an older donor or prolonged cold ischemia time.

\section{Funding/Support}

The authors did not receive financial support for this research.

\section{Conflict of interest/Disclosure}

The authors have no relevant conflicts of interest to disclose.

\section{Supplementary materials}

Supplementary material associated with this article can be found, in the online version, at https://doi.org/10.1016/j.surg.2020. 02.005 .

\section{References}

1. Eurotransplant International Foundation. Eurotransplant statistics library 2018. http://statistics.eurotransplant.org/reportloader.php?report=6356026008\&format=html\&download=0\&action=login. Accessed March 9, 2020

2. Blok JJ, Detry O, Putter H, et al. and the Eurotransplace Liver Intestine Advisory Committee. Longterm results of liver transplantation from donation after circulatory death. Liver Transpl. 2016:22:1107-1114.

3. Callaghan CJ, Charman SC, Muiesan P, et al. and the UK Liver Transplant Audit. Outcomes of transplantation of livers from donation after circulatory death donors in the UK: a cohort study. BMJ Open. 2013;3:e003287.

4. de Vera ME, Lopez-Solis R, Dvorchik I, et al. Liver transplantation using donation after cardiac death donors: long-term follow-up from a single center. Am J Transplant. 2009;9:773-781.

5. Grewal HP, Willingham DL, Nguyen J, et al, Liver transplantation using controlled donation after cardiac death donors: an analysis of a large singlecenter experience. Liver Transpl. 2009;15:1028-1035.
6. Lee DD, Singh A, Burns JM, Perry DK, Nguyen JH, Taner CB. Early allograft dysfunction in liver transplantation with donation after cardiac death donors results in inferior survival. Liver Transpl. 2014:20:1447-1453.

7. Croome KP, Lee DD, Perry DK, et al. Comparison of longterm outcomes and quality of life in recipients of donation after cardiac death liver grafts with a propensity-matched cohort. Liver Transpl. 2017;23:342-351.

8. O'Neill S, Roebuck A, Khoo E, Wigmore SJ, Harrison EM. A meta-analysis and meta-regression of outcomes including biliary complications in donation after cardiac death liver transplantation. Transpl Int. 2014;27:1159-1174.

9. Foley DP, Fernandez LA, Leverson G, et al. Biliary complications after liver transplantation from donation after cardiac death donors: an analysis of risk factors and long-term outcomes from a single center. Ann Surg. 2011;253:817-825.

10. Chan EY, Olson LC, Kisthard JA, et al. Ischemic cholangiopathy following liver transplantation from donation after cardiac death donors. Liver Transpl. 2008; 14:604-610.

11. Buis CI, Hoekstra $H$, Verdonk RC, Porte RJ. Causes and consequences of ischemic-type biliary lesions after liver transplantation.J Hepatobiliary Pancreat Surg. 2006;13:517-524.

12. Verdonk RC, Buis CI, van der Jagt EJ, et al. Nonanastomotic biliary strictures after liver transplantation, part 2: management, outcome, and risk factors for disease progression. Liver Transpl. 2007;13:725-732.

13. de Vries Y, von Meijenfeldt FA, Porte RJ. Post-transplant cholangiopathy: classification, pathogenesis, and preventive strategies. Biochim Biophys Acta Mol Basis Dis. 2018;1864:1507-1515.

14. Kalisvaart M, Schlegel A, Umbro I, et al. The impact of combined warm ischemia time on development of acute kidney injury in donation after circulatory death liver transplantation: stay within the golden hour. Transplantation. 2018;102:783-793.

15. Taner CB, Bulatao IG, Perry DK, et al. Asystole to cross-clamp period predicts development of biliary complications in liver transplantation using donation after cardiac death donors. Transpl Int. 2012:25:838-846.

16. Villa R, Fondevila C, Erill I, et al. Real-time direct measurement of human liver allograft temperature from recovery to transplantation. Transplantation. 2006:81:483-486.

17. Jochmans I, Fieuws S, Tieken I, Samuel U, Pirenne J. The impact of hepatectomy time of the liver graft on post-transplant outcome: a Eurotransplant cohort study. Ann Surg. 2019;269:712-717.

18. Farid SG, Attia MS, Vijayanand D, et al. Impact of donor hepatectomy time during organ procurement in donation after circulatory death liver transplantation: the United Kingdom experience. Transplantation. 2019;103:e79-e88.

19. Hansen $T$, Hollemann $D$, Pitton MB, et al. Histological examination and evaluation of donor bile ducts received during orthotopic liver transplantation-a morphological clue to ischemic-type biliary lesion? Virchows Arch. 2012;461:41-48.

20. op den Dries S, Westerkamp AC, Karimian N, et al. Injury to peribiliary glands and vascular plexus before liver transplantation predicts formation of nonanastomotic biliary strictures. J Hepatol. 2014;60:1172-1179.

21. Watson CJE, Kosmoliaptsis V, Pley C, et al. Observations on the ex situ perfusion of livers for transplantation. Am J Transplant. 2018:18:2005-2020.

22. Matton APM, de Vries Y, Burlage LC, et al. Biliary bicarbonate, pH and glucose are suitable biomarkers of biliary viability during ex situ normothermic machine perfusion of human donor livers. Transplantation. 2019:103:1405-1413.

23. Nederlands Transplantatie Vereniging [Dutch Transplant Society] (NTSDTF) National protocol post mortem donor organ procurement; 2017. https://www. eurotransplant.org/wp-content/uploads/2020/01/H9-The-Donor-Februar2020.pdf. Accessed March 9, 2020.

24. de Vries Y, Matton APM, Nijsten MWN, et al. Pretransplant sequential hypoand normothermic machine perfusion of suboptimal livers donated after circulatory death using a hemoglobin-based oxygen carrier perfusion solution. Am J Transplant. 2019;19:1202-1211.

25. op den Dries S, Karimian N, Sutton ME, et al. Ex vivo normothermic machine perfusion and viability testing of discarded human donor livers. Am J Transplant. 2013:13:1327-1335.

26. Ooms-de Vries KM. Reducing hepatectomy times in all Dutch organ procurement teams. Poster presentation at: Bootcongres; March 14, 2019; Amsterdam, The Netherlands.

27. Hameed AM, Pang T, Yoon P, et al. Aortic versus dual perfusion for retrieval of the liver after brain death: a national registry analysis. Liver Transpl. 2018;24: $1536-1544$

28. Ghinolfi D, Tincani G, Rreka E, et al. Dual aortic and portal perfusion at procurement prevents ischaemic-type biliary lesions in liver transplantation when using octogenarian donors: a retrospective cohort study. Transpl Int. 2019;32:193-205.

29. Otto G. Heise M, Thies J et al. Liver preservation by aortic perfusion alone compared with preservation by aortic perfusion and additional arterial ex situ back-table perfusion with histidine-tryptophan-ketoglutarate solution: a prospective, randomized, controlled, multicenter study. Transplantation Direct. 2017;3:e183.

30. Hessheimer AJ, Coll E, Torres F, et al. Normothermic regional perfusion vs. super-rapid recovery in controlled donation after circulatory death liver transplantation. J Hepatol. 2019;70:658-665.

31. Kalisvaart M, de Haan JE, Polak WG, et al. Onset of donor warm ischemia time in donation after circulatory death liver transplantation: hypotension or hypoxia? Liver Transpl. 2018;24:1001-1010.

32. Feng S, Goodrich NP, Bragg-Gresham JL, et al. Characteristics associated with liver graft failure: the concept of a donor risk index. Am J Transplant. 2006;6: 783-790. 